\title{
TRADITIONAL HEALTH CARE IN SOUTH AFRICA - DIVERSE IDEAS AND CONVERGENT PRACTICE
}

\author{
J.H. Booyens \\ Dept. Anthropology \\ University of Port Elizabeth \\ PORT ELIZABETH
}

\begin{abstract}
The main theme of this paper is a description of the surprising resistance of so-called folk concepts of health and illness to modem scientific medicine. This phenomenon is discussed in a historical as well as a sociocultural context, in order to facilitate understanding. It is indicated that although the methodological dictum of relativism may be initially useful as a heuristic guide to decipher what may be called the 'logic of the irrational' cross-culturally, it may not be elevated to a position of ontological relativism. Ill health sets limits to human autonomy everywhere. Health care, however defined, is thus a universal human need. It must be realized that whatever the different cultural conceptions, taken-for-granted societal and professional power structures may prove to be important stumbling blocks in the delivery of more efficacious health care which modem scientific medicine undeniably can deliver. It is argued that knowledge of differences may be important in the facilitation of cross-cultural understanding. Members of the medical profession must, however, be able to tolerate differences, be aware of the unforeseen consequences of their taken-for-granted structural position as a social category and try to relate to people as autonomous human beings and not as members of conventional and thus stereotyped cultural or social categories.
\end{abstract}

\section{INTRODUCTION}

The aim of this paper is not to give a detailed exegesis of the so-called traditional health care system(s) in South Africa, although it will be touched on briefly. The main aims are rather to give a brief overview of the cultural and historical context of health care systems with special reference to South Africa. As will be indicated, health care and universal conceptual and practical systems which address the problems of health and disease, are embedded in culture and society at a much more profound level than the formal legal recognition of scientific medicine and its ancilliary services tend to reflect.

Although the aforementioned may not be a revolutionary revelation, it should be regarded as a broad, but also dynamic, frame of reference in any discussion of the problems of modern medicine, with regard to its relationship with patients and other health care systems. This is perhaps of particular concern, because ethics is basically involved with relationships. In this regard, modern institutions, including modern 
medicine - in spite of its success as an applied science - are criticized for their neglect of the person (patient) in the total socio-cultural context (cf. Lyng, 1988:106-108).

In this paper, the importance of health as a basic human need, the problem of viewing health and illness from an cultural anthropological perspective and the issue of the existence of different health care systems and their interrelationship, will be touched upon. This will be followed by a short general discussion of these themes within a developmental framework, as seen from different theoretical perspectives.

\section{HEALTH AS BASIC HUMAN NEED IN SOCIO-CULTURAL PERSPECTIVE}

Amongst anthropologists today it is more or less regarded as a truism that humankind's relations with nature are culturally mediated. Culture may thus in a broad sense be seen as a 'theoretical' construct used to order reality and interpret experience. Interpretations, therefore, are not derived directly from experience, but imposed upon it. The meaning of experience may thus be relative and not universal (cf. Doyal, \& Harris, 1986:13).

Cultural relativity must, however, be viewed against the natural and social constraints placed or forced upon human beings. The constraints are limiting factors imposed on the general flow of human activities. Bronislaw Malinowski viewed the limiting factors as the fulfillment of basic human needs. Malinowski (1960:90) wrote:

By need, then, I understand the system of conditions in the human organism, in the cultural setting, and the relation of both to the natural environment, which are sufficient and necessary for the survival of group and organism. A need, therefore, is the limiting set of facts. Habits and their motivation, the learned responses and the foundations of organization, must be so arranged as to allow the basic needs to be satisfied.

This was an early formulation of the involved search for primary prerequisites of human socio-cultural existence in classical functionalist social science.

\subsection{Need for health and autonomy}

More recently, and viewed from a somewhat different perspective, the satisfaction of basic human needs is also stressed in the Sociology of Development. Basic human needs include both material needs like adequate food, shelter and, related to these, education, health care and employment, as well as non-material needs. The last mentioned relate to the need for expression, creativity, equal treatment, real living together and continuous efforts towards mastery of one's life-world (cf. Coetzee, 
1989:102). The importance of soundness of health within the context of primary needs satisfaction in order for humans to realize their personhood, is stressed by Doyal and Harris by their seduction of these needs to two interrelated facets: the need for health and autonomy. This reasoning is based on the presupposition that for humans to be persons, they must be able to act and not simply be acted upon (Doyal \& Harris, 1986:171). Ill-health, whether physical or psychological, constrains people in the performance of their normal social roles. It also relates to human autonomy which may be defined as the capacity to be creatively active through the ability to formulate aims and beliefs, to choose to put them into action and be responsible for the resultant actions in the knowledge of at least their immediate consequences (Doyal \& Harris, 1986:172)

Autonomy, in the above sense, does not imply a radically free individual. Individuals do need some sense of ontological security (Giddens, 1984:7). It is rather an acknowledgment that humans are knowledgeable agents bound by unconscious and unacknowledged conditions/unintended consequences of actions (Giddens, 1984:281282). But meaning is also socially constructed and intentions to act and actions themselves, can only be meaningful within a framework of rules, whether the individual chooses to abide by or break the rules. The identification of an act as intersubjectively meaningful, presupposes a group of persons accepting certain conventions and who agree upon social constraints, which have to be continually reproduced or enacted (cf. Doyal \& Harris, 1986:74,85).

Learning to act and learning how to follow or break the rules or conventions, are the essential ingredients of being human and a cultural being.

\subsection{A Christian point of view?}

From a Christian point of view, there may be objections to the tenet that basic human needs revolve around health and autonomy. It may thus be argued that this proposal implies that human endeavours relate to the horizontal plane only and it does not take into consideration the possibility that ill-health may to some people be a deep and meaningful spiritual experience.

However, Christ, during his ministry on earth did not ignore human physiological and psychological suffering. It seems that from both a Christian and a humanistic point of view, a strong argument may be made for caring for people and their needs. For meaningful human day to day functioning in the present dispensation, the maintenance of good health, therefore, does seem to be a real limitiıg factor, i.e. a basic human need. 


\subsection{Healing and cultural views}

It is in the above relativistic/universalistic context that the universal constitutive activity of healing and concomitant cultural specific views on illness can be discussed. Healing can be regarded as a universal constitutive activity, because its practical intent can be recognised cross-culturally. Similarly, putting plans into action to get food, another constitutive activity, would perhaps only baffle the most naive of human observers. These activities are thus like transparent avenues towards cross-cultural understanding. Furthermore, the retention and attainment of health entail one of the areas of human practical agreement which makes specific (relativistic) forms of cultural life - with striking variation in content - materially possible (cf. Doyal \& Harris, 1986:152). A contextual framework for grasping cultural specific theories of illness is, however, not complete if the impression is created that specific actions are of necessity only determined by traditional beliefs. This may well be the case, but historically derived situational constraints should also be taken into consideration.

\subsubsection{Culture as resource}

In this regard it may be useful to view culture or conventional views and plans/rules for action as universal human resources. As a resource culture is, however, especially in complex societies, differentially distributed (cf. Keesing, 1981:364; Thornton, 1988:24). Most societies in the world are for instance, characterized by some form of division of labour. An unforeseen consequence of this may be unequal access to the pool of cultural resources. This may well be balanced by complementarities and reciprocities, but differences in life-styles may and do actually reflect differential access to resources needed and desired by people, because of the structuring of social power (cf. Ortner, 1984:155; Thornton, 1988:24).

On one level, it may therefore be helpful to explain actions by tradition (the reproduction of shared conventions as intended by people). The continuities and changes in traditions are, however, also embedded in historically derived meanings and functions and these must also be taken into consideration and not only the differences to explain differences (cf. Thornton, 1988:25).

\subsubsection{Internalizing cultural concepts}

The complexities of coming to grips with the reasons for actions also relate to what Spiro (1986:328-329) called the hierarchy of cognitive salience. He indicates that the psychological transformation of cultural concepts, as part of personal beliefs, depends 
upon the characteristics of social relations, in the sense that people acquire culture from significant others. Depending on the relations, people may learn about propositions, they may also come to understand their meanings and the way they are interpreted. This may lead to internalization, i.e. it may become part of what the individual holds as true or right, which may in turn serve to structure the persons perceptual world, hence guiding their actions and ultimately, in possessing emotional, motivational and cognitive salience, to instigate action.

The problem is, however, that even when a conceptual scheme is - so to speak - seen in action, it is not immediately evident to what degree it is internalized (cf. Kaplan \& Manners, 1972:118). For example, the superficial quantification of perceived actions in the health seeking behaviour of people as an indication of deep seated emotional attachments to traditional conceptions - or for that matter latter acquisitions - may be quite misleading. The intentions of participants may vary substantially from person to person. The intentions or levels of internalization are thus matters for empirical investigation and can not be taken for granted (cf. also West 1977:189-206).

\section{THE SOCIAL CONTEXT OF TRADITIONAL HEALING IN SOUTH AFRICA}

In South Africa different systems of medicine and regimes of resort exist and are available. This may be regarded as yet another indication of the importance people attach to the need for health.

The system, variously known as modern, scientific, cosmopolitan, allopathic, or biomedicine, however, is without doubt widely accepted as the most advanced and prestigious. It has even been stated that American and European power and cultural hegemony have assured its dominance over other systems of medicine throughout the world (Salmon, 1984:3). The roles of professionals within this specialised system, which includes paramedical professions, are not widely shared. They must, however, be regarded as part of the - at least cognitively shared - cultural resources of most people in South Africa, because of a general agreement that these roles should exist (cf. for instance Booyens, 1984:467).

\subsection{Fringe categories of health care systems}

Other health care systems also exist, variously called alternative, fringe or in more derogatory terms, deviant. Systems like homeopathy, osteopathy and chiropractice, naturopathy, acupuncture, hypnotherapy, Christian Science and Radiesthesia amongst 
others, are known and variously enjoy acknowledgement as subsidiary to scientific medicine. However, from a professional point of view, they may be regarded as downright dangerous or elaborate placeboes.

The system of traditional healing with its concomitant views on healing practices and views on the etiology of disease may also be regarded, from the point of view of practitioners of scientific medicine, as belonging to the fringe category of healing systems.

From a scientific point of view, lay people may, however, relate to different systems or theoretical constructs or conceptual commitments, regarding systems of healing, which from a Kuhnian vantage point are seemingly incommensurable. This seems to be possible because most people are not scientists. In their desperate search for the alleviation of suffering, people also do not necessarily, in the first instance, want to confirm their system of belief. Their actions may even mean that they are handicapped by a socio-structural constraint, or that they are manipulating the system. The real retention of different systems themselves, however, must also be seen within the context that experience must be interpreted and that experience itself cannot simply be used to decide between rival systems of belief which dispute each others overall meaning (cf. Doyal \& Harris, 1986: 13).

\section{HEALTH CARE SYSTEMS}

The above reference to lay people also implies that, what may be called health care systems, do not only concern professionals. In this regard it may be helpful to follow Kleinman's distinction between different sectors in the health care system, viz. the popular sector, the professional sector and the folk sector (Kleinman, 1984:140 - 153).

\subsection{The popular sector}

The popular sector or lay sector is the sector of lay intervention during perception of illness and consists of individuals, networks of family and friends. It is within this sector that illness is first experienced, labelled (named $=$ diagnosed) and treated. It includes a very wide variety of health maintenance and curative measures. Most symptoms treated in this sector are minimal and self-limiting. Nevertheless, most health care takes place in the popular sector. Helpseeking and decisions regarding compliance are also made in this sector. 


\subsection{The professional sector}

The professional sector consists of both the professional system of scientific medicine and in some countries certain alternative systems, like the osteopathy and chiropractic professions. In India, China and Pakistan, there are also indigenous healing professions. A trend towards professionalization amongst indigenous healers is also observable in South Africa. For instance, an association known as The Professional Herbal Preparations Association of Inyangas exists with its headquarters in Johannesburg.

According to Kleinman (1984:146), the explanatory systems of indigenous healing professions are often closer to the lay health culture. Within the professional component of healing systems, however, a disease (somatic, theoretical) orientation rather than an illness (somatic, experiential) orientation is produced. (People experience illness - doctors diagnose and treat disease.)

The disease orientation, according to Lyng (1988:109-110), implies a reductionist view of ill-health. He came to the conclusion that this orientation originated from three interrelated social-structural factors, viz. the influence and high status of the positivist scientific model, secondly, being an applied scientist, the practitioner in seeking to cure a disease reduces it to histopathology, thereby making it amenable to manipulation by the individual practitioner and thirdly, the practitioner cannot easily escape from an environment where the activities of powerful interest groups are tied to the health status of the population. Thus, by 'ignoring' social variables, a restricted medical perspective is more likely to survive. A fourth factor could be added, namely the predominantly anonymous urban environment with its shifting population of patients and doctors (cf. Eisenberg, 1985:42).

The modern professional disease orientation also tend towards a more formal relationship with patients. Western professionals also tend to control knowledge and decisions as to when and how to communicate parts of it. They encourage a distinct separation between themselves and clients and are controlled by professionally dominated boards. The result is that they view clients as passive and not active consumers and encourage client dependency. They also like to adhere to structured routines for providing services (cf. Biklen, 1983:202-203). However, everywhere, signs of cultural borrowing are to be observed, especially from scientific professional medicine (Kleinman, 1984 $: 147,148$ ). Cultural borrowing also takes place between the different popular systems in heterogeneous societies and between the professional and folk health care systems. 


\subsection{The folk sector}

The folk sector comprises of what Kleinman categorizes as the non-professional, nonbureaucratized 'specialists' (1984:148-149). The 'specialists' may include healers whose system of healing is based on secular and supernatural conventions. Usually they are individual practitioners who practise outside formal institutional settings and the basis of their system of healing is often widely shared conventions and it blends into the lay or popular sector(s). In the South African context, they include different kinds of healers belonging to the category of fringe or alternative medicine, including so-called traditional healers (diviners and herbalists) and prophetic healers associated with the Indigenous or Independent Black churches.

The above categorization of health care systems must be regarded as an oversimplified descriptive instrument. As already indicated with reference to cultural borrowing, health care systems are dynamic inter- and intra-cultural processes. More often than not, the process of interaction gave rise to syncritistic synthesis, a wellknown outcome in situations of acculturation. Kleinman himself warns that each of the systems is plural and highly diverse (Kleinman, 1984:140).

\section{TRADITIONAL HEALING IN A CULTURAL HISTORICAL PERSPECTIVE}

It is possible to relate the history of ideas about health and illness to different world views; these may include magical, religious and secular world views. For the purposes of this presentation, a world view may be defined as a cognitive attempt to make sense of the world, and to impose meaning on it (Hammond-Tooke, 1989:33).

It is well-known that modern science and the development of modern medicine are of quite recent origin. Before the sixteenth century, the problem of reality (ontology), the nature and limits of knowledge (epistomology), the way enquiries should be pursued (methodology) and definitions of what knowledge and truth were supposed to be, did not sharply separate facts from values or the objective from the subjective. Objects and natural processes were analysed and classified as being in a more organic relationship with the universe. The separation of events as 'things' and evaluative relations in which the world is seen as a set of interacting facts, is part of the modern scientific view of the world (Young, 1981:63, 64). In the modern view, decisions should be subjected to value free rational choice in accordance with technical rules. This is a kind of instrumental rationality by which control should be established over the factors at hand (cf. Fay, 1975:44).

Historically speaking, there seems to be a close relationship between the need for 
control over nature, changes in the production of goods and services, population pressure, centralization of political power and scientific development.

In the Western world, one of the (unforeseen?) consequences of these events was the gradual development of a dualistic view of reality, inter alia the divorce between scientific and religious values and knowledge.

\subsection{World view and healing}

A very old theme in the history of humankind seems to be precisely the struggle for control over knowledge, whether religious or secular. Following Max Weber, Wax (1968:229-241; cf. also Pauw, 1975:7-16), for instance distinguishes between the Great and Little Tradition as religious or perhaps world view systems and indicates the perpetual tension between them since the times of classical antiquity. According to this analysis, the Little Tradition is equated with what may be called the magical world view and its polytheistic formalization in classical antiquity. The Great Tradition refers to the radical critique of the Little Tradition and its polytheistic successors and contemporaries by ascetic and rational prophets and philosophers. In the Great Tradition, issue is taken against conventional morality according to which prosperity is necessarily a measure of morality, whilst at the same time preaching self-restraint and subjugation of the passions (Wax, 1968:239). This tension and struggle is still continuing in modern times.

In the West another factor has arisen, namely that the 'high priests' of science and the Church, which, although both valuing comprehensive, rational systematization, came into conflict. But, because within the positivistic tradition, science is erroneously viewed as value free and therefore more rational, it seems to be winning the struggle against the Church. The outcome is not yet conclusive. Furthermore, as Pauw has pointed out, many Westerners value the quest for systematization and recognize comprehensive rational consistency as a value of modern culture. However, many others have little concern for this value, and it may sometimes even be scorned (Pauw, 1975:334 ; also Hammond-Tooke, 1989:28; Furnham, 1988:2-7). The view that science and progress should be regarded as two sides of the same coin, is also questioned especially with regard to nuclear energy and high-technology medicine (Young, 1981:65)

To summarize then, with reference to the main theme, the different healing traditions in South Africa include those based on what may be called a magical world view, a religious world view and a scientific world view. All are value laden and variously intermixed, containing their own brands of mysticism, pragmatism and rationality (cf. 
Pauw, 1975:13). A healing tradition sometimes is a relationship characterized by various degrees of tension.

Historically and especially with regard to formal contact between Westerners and the indigenous people of South Africa, contact between exponents of the Christian Great Tradition (missionaries) frequently also includes efforts of intervention in the health sphere. This contact set the scene for the age old struggle between traditions with radically different views of the world. As Burrows (1958:180) succintly put it in a somewhat different context, with reference to the commissioning of the hospital at King William's Town more than a century ago:

The opening of the hospital on the 11th of June, 1859 was a great event in Africa. For it meant that the first round had been fired in the long arduous battle to break the power of the native (witch) doctors among their own people.

\subsection{The relationship between people and environment}

As a simplified anthropological construct, it may be said that the indigenous people, inhabited a world viewed as a 'society' composed of 'beings' rather than 'objects'. The phenomena of 'nature' were regarded as 'fellows' rather than objects. Health and prosperity therefore relate to a good or bad relationship between people and the environment (cf. Wax, 1968:235). The human actors did not as a rule seek mechanical control over a world that is a 'society'. Rather, a beneficial relationship was sought, a relationship in which the inherent power of being could be enhanced. A beneficial relationship not based on chance, was manifested in this - worldly success, health and good fortune (Wax, 1968:238). Misfortune and ill-health thus gave rise to the wellknown question of 'why me?' and 'who is responsible? - the classical statements of systems of personalistic etiology. It may be noted that the same kinds of questions are also asked by modern people, even though they may seldom act upon them.

\subsection{Social structure and religious beliefs}

Cross-culturally there are also clear indications that specific systems of belief are to a large extent congruent with certain social-structural features of societies. There seems to be a correlation between the complexity of social structure and religious beliefs, ranging from monotheism, polytheism, to the absence in beliefs in what could be called 'high gods'. In modern industrial society, although extremely complex, the tradition of sceptical enquiry and attempts towards demystification even allows for atheism. In this tradition the belief in the supernatural is displaced by the belief that rational, unbounded man should work out their own salvation. Ironically, this is somewhat 
similar to a this-worldly orientation in the 'magical world'.

\section{THE INDIGENOUS LITTLE TRADITION IN SOUTH AFRICA}

In South Africa the traditional indigenous 'magical' world view (Little Tradition) may be summarized as consisting of five loosely articulating theories, which explain according to their own logic the presence or absence of prosperity in the human condition (cf Hammond-Tooke, 1989:33-34, 46-50).

* The supreme being: A vague, perhaps even residual explanatory concept, utilized much like the concepts of 'luck' or 'chance'.

* The ancestors: A central explanatory category, whose importance reflects the status hierarchy of the kinship system of the living. The ancestors are believed to look after the interests of their living kinspeople. They can send illness and misfortune if, as the usual explanation goes, rites during the important phases of the life cycle are not properly performed and respect is not accorded to senior members of the descent group.

* Witchcraft/sorcery: Witches and sorcerers are usually kinsmen or neighbours and also fellow workers (in the modern context), who may be regarded as bearing the theodetical blame. While they are driven by envy and malice in bringing harm to others. They are the ones who actually try to manipulate relations between the forces or powers inherent in the cosmos to do harm, they must be counteracted.

* Pollution beliefs: This category relates to ritual impurity or pollution. People, like for example widows, women who have had a miscarriage, menstruating women, and persons who have handled a corpse, are all regarded as polluted. People in this state may have diminished resistance to disease,. and may also cause illness in others. Pollution beliefs may also relate to witchcraft in the sense that a polluted person may deliberately harm others by his or her presence (Booyens, 1986(a):1314).

- 'Natural' causation: There are indications that this category of illness may be related to ideas about the 'supreme being'. The causes of illnesses with a widespread epidemiology may, for example, find expression as 'the way the earth was created' (cf. Booyens, 1986(a):10-12).

These views were and are variously shared by lay people (the popular sector) and the folk sector. 


\subsection{Specialist bealers}

In the folk sector of the health care system, it is possible to distinguish between different types of traditional indigenous healers, namely the diviner and the herbalist. Both are specialists, but only the diviners are called by the ancestors to their vocation. The herbalists are dispensers of medicine, although each household also knows at least some medicines and the majority of minor ailments are probably treated by household remedies, as is the case in the popular sector of all cultures. Another specialist category is the midwife.

As stated earlier, the above simplified synopsis of the indigenous system of belief and theories about the human condition must be seen against a background of accelerated change. Formal education, industrialization, urbanization and missionary work have brought about a differentiation of ideas about reality and also a mixing of diverse indigenous cultural traditions and western lay and scientific traditions.

An important consequence of this was not only the acceptance of scientific medicine, but also the creation of yet another category of healer, the Zionist prophet. This relates to the healing ministry of the Pentecostal form of the Christian church. In these churches, of which thousands exist, emphasis is placed on faith-healing through the work of the Holy Spirit (cf. Hammond-Tooke, 1989:51-52; also West, 1977:194; and Booyens, 1986(b):118-124)).

\section{THE CONTEMPORARY SCENE}

As far as health care systems are concerned, the reality of the South African scene is a mixed bag of different and incongruent practices and beliefs. Although officially and legally the health care system has been constructed around modern scientific medicine, it has never been, as is the case elsewhere in the world, accepted as the sole health resource.

The continued existence of aspects of the 'magical' world view amongst members of the black section of the South African population are attested to by study after study. In this regard Hammond-Tooke $(1989: 8,9)$ remarks that the exigencies of individual life experience mean that almost all people develop hybrid world-views which help them to make sense of experience and action. Although people adopted scientific medicine, they still retain traditional concepts when they find it necessary to impose significance on their experience. He is also of the opinion that although the use of traditional conventions may be seen as a symbol of resistance because of the traditional power differentials in South Africa, traditional health ideas and practices can 
also be regarded as being accepted for their own sake, as efficacious therapy.

\subsection{Efficiency of traditional healing}

This inevitability leads to the pragmatic question of the efficacy of traditional healing. In South Africa, systematic studies related to this question are, unfortunately, nonexistent. Impressionistic views may even be biased in favour of traditional healing practices. Elsewhere, according to Kleinman (1984:150-152) the few systematic studies of which the findings have been published since the beginning of the eighties, indicate that traditional healers are frequently effective, that there are limits to their efficacy, and that, while toxicities of traditional healing are infrequent, they do occur. The findings with regard to psychiatric disorders are still inconclusive. The few available studies indicate good results in cases of acute stress-induced psychosocial and psychophysiological problems and mild neurotic disorders (Kleinman, 1984:152). Although the efficacy of some biological active drugs in use are known, the sources of the efficacy of traditional healers still await the systematic study of psychosocial and biological interaction (Kleinman, $1984: 152$ ).

In view of these tentative findings, professional pride should perhaps be reassessed, because these findings indicate the urgent need for a more objective look at alternative health care systems in South Africa. Whether the formal integration of the traditional system and scientific medicine is possible is, however, a controversial question and perhaps even impossible to attain (cf. Hammond-Tooke, 1989:145-155).

\section{ACCESS TO SCIENTIFIC HEALTH CARE IN SOUTH AFRICA}

It is generally acknowledged that the health care situation in South Africa is inadequate. If the services of professional scientific medicine - which are criticized as being too mechanical and impersonal - are regarded as the most efficacious, there nevertheless seem to be quite extensive areas of inadequacy. These relate to doctorpatient ratios amongst different sections of the population, the scope of medical aid schemes, the concentration of facilities in urban areas, the underemphasis on preventive and primary health care and the fragmentation of services (cf. Krige, 1990:54; also Wilson \& Ramphele, 1989:100-120).

This situation could be seen as conducive to the continued existence of traditional medicine. The maintenance of the system of folk healers is thus in one sense a function of the lack of facilities accessible to especially black people. This can, however, be seen as somewhat of an oversimplification in view of the growing use 
whites make of so-called fringe medicine. However, in view of their economic position, most whites probably consult so-called fringe practitioners or folk healers out of choice, and not immediate necessity. Surveys also clearly indicate that amongst black people a growing trend away from reliance on indigenous healers exists (cf. Booyens, 1984:466-493; Edwards, 1986:90-93; Farrant, 1986:97-103). This implies that black people actually want the services rendered by scientific medicine. The phenomenon that they, like whites, do make use of resources in all health care systems may therefore not be used as an excuse for the sparse distribution of professional health care facilities.

Consideration must, however, also be given to resistance to change which plays an important role in the maintenance or at least partial maintenance of customs. In the rural areas of the Transkei for instance, up to the late nineteen seventies, about half the population identified themselves as 'Reds'. This is a category of Xhosa-speaking people which to a large extent had been resisting Western cultural incursion for more than a century (Mayer, 1980:2). Mayer is of the opinion that in certain urban areas, like Soweto, there may even be an upsurge in ancestor religion among black people. Behind this phenomenon is a desire to resist white domination (Mayer,1980:69).

\section{SOME DEVELOPMENTAL CONTROVERSIES}

Within a broad, world-wide framework, a bitter controversy is raging amongst social scientists over the explanation of phenomenon like differential access to basic human resources, poverty and so-called underdevelopment. The two main contenders up to quite recently were modernization theory and the expanding of underdevelopment or dependency theory. Both these approaches have their roots in optimistic evolutionist social science of the nineteenth century. An overly simplified synopsis of the theoretical stances of these schools of thought, is the following:

\subsection{Modernization theory}

Amongst Western social scientists modernization theory or in anthropological parlance, diffusion/acculturation theory, may be regarded as the elder brother. Perhaps its main feature is a 'blame the (traditionalistic) victims'-syndrome. Accordingly underdevelopment is seen within the framework of a dualistic traditional/modernist model. Its main exponents see the lack of development, inter alia poverty and health problems, as the devotion to irrational cultural values by members of societies in the Third World. Its main weakness is contextual naivety and the reification of human constructions, like culture, ethnicity and the market. 


\subsection{Dependency theory}

Dependency theory's main feature is a 'blame the (capitalistic) system' syndrome, whether it be the world - or a local system. It originated during the sixties as an alternative (neo-Marxist) explanatory model. This theory is based on dualistic structural analysis, in the sense that it concentrates on the exploitive relationship between social phenomena, and especially the 'have's and have nots' (centre and periphery). Its main weaknesses are the deterministic explanatory use of modes of production and the view that the have nots' ideas about the world are based on a false consciousness. However, it provided a useful alternative to the view that racial and ethnic categories are somehow isolated primary realities (natural givens) divest of creative human manipulations of interests (cf. Sharp, 1988:176-177). In a sense, however, it is a mirror image of modernization theory in that it merely redefines the 'us' and 'them' and, like modernization theory, tries to plan the future for the victims (cf. Sharp, 1989:120 and Holscher \& Romm, 1986:121-122).

\subsection{Development theory}

How does the above digression into development theory fit into the main theme? I believe that the givens of the health care situation in South Africa makes it imperative to take a closer look at various ways which have been proposed as possible solutions for poverty and its concomitant problem of ill-health (the diseases of affluence seem already to get the attention they deserve).

In evaluating any scientific theory or explanatory proposition, it is, however, necessary to keep the following statement, as expressed by Fay (1975:25), in mind:

(Science) can provide only conditional laws, and these conditional laws can only be used for unconditional predictions when the conditions in question can be taken as given; it is for this reason that long term unconditional predictions are possible only if the systems to which they apply are well isolated, stationary and recurrent ... (These) are not the conditions of social systems.

This seems to be a very pessimistic view regarding the use of social scientific data for policy purposes. But policies aiming towards a better human future, should always consider the necessity to study both sides of the social coin (cf. Doyal \& Harris, 1986:169). Both the ideas and intentions of people and the structures or unintended consequences of action must be scrutinized and the ever surprising contingencies be faced. In planning for health care, it must be remembered that 'we' and 'they' are not homogeneous and isolated entities, 'our' dominant ideas about reality, as perhaps part of the modern Great Tradition, may have real consequences for 'them', not always 
intended by 'us'.

Views of the world may very well be different, but, because of the reality of actual limits (basic needs) to meaningful human existence, it will at the very least be possible to enter each other's worlds by saying a mutual no to some forms of human suffering (cf. Berger, 1977:259). This may serve well as a point of departure for a process of the necessary continual ideational and practical dialogue amongst people and not conventionally defined categories. This should be a move away from cross-cultural (mis)understanding towards (dis)agreement on particularistic cultural content. It implies, in conjunction with the necessary understanding, a more profound level of tackling the mutual concern for human suffering.

\subsection{Technocracy and human responsibility}

The above mentioned premises also include self-evaluation. Everywhere in the world there seems to be a re-evaluation of what could be called the technocratic modern project. In the South African context, the supporters of this project have undeniably reaped richly from the material benefits of this view of the world, and its accompanying practices. However, South Africans are also confronted with skewness in the distribution of cultural resources of which one of the most basic is access to and the rendering of scientifically based health care.

A question with important ethical implications emerges from the use, abuse and distribution of resources. Is the present world system, which is being dominated by the so-called technocratic world view and its concomitant economics of consumerism, only the beginning or perhaps the end of the meaningful survival of humankind? Some would say it is the beginning of the end. Modern humans are, in this view, trapped in a vicious circle of wants, in which their fulfillment and enrichment pauperize nature. This is done to such an irrational extent that the ecological balance has perhaps been lost. What is seen as development, is therefore actually only part of a desperate race to stay ahead of disaster (cf. Lemaire, 1976:112). This seems to be indeed a poor but perhaps also a controversial prognosis, but somehow and perhaps because of the successes in material elaboration, human responsibility towards all creation seems to have been lost to greed.

Perhaps the concept development which grew out of the Enlightenment's idea of progress and subsequent evolutionism with its implied ethnocentrism, should be reassesed. As one of the master symbols of modernity, it has especially in its narrow technocratic sense given rise to frustation with and contempt for the 'others'. As has already dawned upon quite substantial numbers of people and organizations, stress 
must rather be placed on broadly based interdisciplinary and holistic service institutions with, and for people in localities and communities. Members of the profession of modern medicine should in this regard, however, take note that experience has taught that in general and for various reasons, they tend not to work well as interdisciplinary team members (Gulati \& Guest, 1990:66).

\section{CONCLUSION}

Whatever our views on development and its relationship to socio-cultural differences, the particular South African facts of the matter are that starvation and ill-health exacerbated by apartheid - are part of the system, but so are professionals. It seems as if members of the medical profession should ask themselves whether this situation can still be tolerated. They must decide whether it is ethically justifiable to work long hours treating symptoms - seemingly allowing themselves to be pressurized into viewing ill-health only as morbid anatomy.

It has always been the view from the perspective of the Christian philosophy of science that a value-free science is impossible. In my understanding of this premise, it implies a radical break with the Cartesian dualistic view of humankind. Man, in his dimensions of faith, rationality, psychicality and body, is one. This article must therefore be regarded as yet another plea for a more holistic view of medicine. It is perhaps no accident that the word healing in English is derived from the original Anglo-Saxon word with the meaning of being whole. In its broadest sense, healing refers to reintegration and even reconciliation, not only spiritually, psychologically, cognitively and bodily, but also socially. This seems to be the ideal process which should be strived towards.

As a first step towards reaching this ideal, professionals should become more closely involved with people, in the communities which they serve - or at least materially help those of their members who want to get involved. This could perhaps also mean less control over knowledge, less control by professionally dominated associations, less control over decision-making, less routinization and less consumer dependency, in order to penetrate cultural and socio-economic barriers of uncertainty, fear and suspicion. This is likely to contribute towards the rendering of a more meaningful and efficacious health service. 
Traditional health care in South Africa: diverse ideas and convergent practice

\section{BIBLIOGRAPHY}

BERGER, P.L. 1977. Pyramids of sacrifice: political ethics and social change. Bungay : Pelican. BIKLEN, D.P. 1983. Community organizing: theory and practice. Englewood Cliffs : Prentice-Hall. BOOYENS, J.H. 1984. Etnomedisyne onder Tswanasprekende stedelinge. Potchefstroom. (Ongepubliseerde proefskrif, PU vir CHO.)

BOOYENS, J.H. 1986(a). Etiologiese beskouinge van Tswanasprekende stedelinge. Suid-Afrikaanse Tydsknif vir Etnologie, 9(1):3-25.

BOOYENS, J.H. 1986(b). The etiological framework and the diagnosis of illness by prophets and sangomas - a comparison. (In Oosthuizen, G.C. $e d$. Religion alive: studies in the new movements and indigenous churches in Southern Africa. Johannesburg : Hodder \& Stoughton. p. 116-125.)

BURROWS, E.H. 1985. A history of medicine in South Africa. Cape Town : Balkema.

COETZEE, J.K. 1989. Development is for people. Johannesburg : Southern.

DOYAL, L. \& HARRIS, R. Empiricism, explanation and rationality. London : Routledge \& Kegan Paul.

EDWARDS, S.D. 1986. Attitudes to disease and healing in a South African context. (In Oosthuizen, G.C. ed. Religion alive: studies in the new movements and indigenous churches in Southern Africa. Johannesburg: Hodder \& Stoughton. p. 90-96.)

EISENBERG, L. 1985. Is there too much science in medicine or not enough. (In McHugh, S. \& Vallis, T.M.eds. Illness behavior: a multidisciplinary model. New York : Plenum. p. 31-50.)

FARRANT, D. 1986. Choice and perception of healers among black psychiatric patients. (In Oosthuizen, G.C. ed. Religion alive: studies in the new movements and indigenous churches in Southern Africa. Johannesburg: Hodder \& Stoughton. p. 97-104.)

FAY, B. 1975. Social theory and political practice. London : Allen \& Unwin.

GULATI, P. \& GUEST, G. 1990. The community-centered model: a garden-variety approach or a radical transformation of community practice. Social Work, 35(1):63-68.

FURNHAM, A.F. 1988. Lay theories - everyday understanding of problems in the social sciences. Oxford : Pergamon.

GIDDENS, A. 1984. The constitution of society. Oxford : Polity.

HAMMOND-TOOKE, D. 1989. Rituals and medicines. Johannesburg : Donker.

HOLSCHER, F. \& ROMM, N. 1986. Development as process of human consciousness: elements of a humanist view on development. (In Coetzee, J.K. Development is for people. Johannesburg : MacMillan. p. 108-136.)

KAPLAN, D. \& MANNERS, R.A. 1972. Culture theory. Englewood Cliffs : Prentice Hall.

KEESINGS, R.M. 1981. Cultural anthropology: a contemporary perspective. New York : CBS.

KLEINMAN, A. 1984. Indigenous systems of healing: questions for professional, popular, and folk care. (In Salmon, WJ. ed. Alternative medicines: popular and policy perspectives. New York : Tavistock. p. 138-164.)

KRIGE, D. 1990 . The basic needs approach to development: the question of health care for black people in Natal. Development Southem Africa, 7(1):53-66.

LEMAIRE, T. 1976. Over de waarden van kulturen. Baarn : Ambo.

LYNG, S. 1988. Theoretical observations on applied behavioral science. The Journal of Applied Behavioral Science, 24(1):101-117.

MALINOWSKI, B. 1960. A scientific theory of culture. Cape Town : Oxford UP.

MAYER, P. 1980. Black villagers in an industrial society. Cape Town : Oxford U.P.

ORTNER, S.B. 1984. Theory in anthropology since the sixties. Comparative studies in society and history, 26(1):120-166.

PAUW, B.A. 1975. Christianity and Xhosa tradition. Cape Town : Oxford.

SALMON, J.W. 1984. Alternative medicines: popular and policy perspectives. New York : Tavistock.

SHARP, J. 1988. Two worlds in one country: "first world" and "third world" in South Africa. (In 
Boonzaier, E. \& Sharp, J. eds. South African keywords. Cape Town : David Philip. p. 111-122.)

SPIRO, M.E. 1986. Some reflections on cultural determinism and relativism with special reference to emotion and reason. (In Shweder, R.A. \& LeVine, R.A. eds. Culture theory. London : Cambridge U.P. p. 323-346.)

THORNTON, R. 1988. Culture: a contemporary definition. (In Boonzaier, E. \& Sharp, J. eds. South African keywords. Cape Town : David Philip. p. 17-28.)

WAX, M. 1968. Religion and magic. (In Clifton, JA. Introduction to cuitural anthropology. New York : Houghton. p. 225-242.)

WEST, 1977. The shades come to town. (In Whissen, M.G. \& West, M. eds. Religion and social change in South Africa. Cape Town : David Philip. p. 189-210.)

WILSON, F. \& RAMPHELE, M. 1989. Uprooting poverty: the South African challenge. Cape Town : David Philip.

YOUNG, R.M. 1981. Why are figures so significant? The role and the critique of quantification. (In Miles, I. \& Evans, J. eds. Demystifying social statistics. London : Pluto.) 
